\title{
How Many Learning Disabled Are There? The Rhetorical Power of Statistics in the Israeli Discourse on Learning Disabilities
}

\author{
Ofer Katchergin \\ Oranim Academic College, Kiryat Tiv'on, Israel \\ Email: ofer k@oranim.ac.il
}

Received 25 July 2015; accepted 12 September 2015; published 15 September 2015

Copyright (C) 2015 by author and Scientific Research Publishing Inc.

This work is licensed under the Creative Commons Attribution International License (CC BY). http://creativecommons.org/licenses/by/4.0/

(c) (i) Open Access

\section{Abstract}

The intention of this article is to problematize the current understanding of learning disabilities by scrutinizing the historical and social context in which they are embedded. The first part of the article lays out theoretical assertions from various fields: sociology of knowledge, rhetoric of science, rhetoric of statistics and historical critical discourse analysis. Integrating these constructionist approaches and through a short historical presentation of the evolution of the discourse and the various critiques that are developed from it, the article reveals the obscurity that surrounds the concept of learning disabilities. In the second part, the article examines one important idiom which forms the basis for the Israeli disabilities discourse: the statistical one which deals with the percentage of disabled persons in the population. Through an analysis of major texts of the Israeli disabilities field and interviews with professionals, it becomes clear how central statistical assertions are shaped into "scientific facts", even when their scientific foundations are quite shaky. The article's aim is to contribute to the development of a more complex disabilities discourse by uncovering its social, historical and cultural contexts. Another aim is to raise awareness to possible uses of statistical knowledge as a discursive and rhetorical tool.

\section{Keywords}

Sociology of Knowledge, Critical Discourse Analysis, Medicalization, Statistical Data (Social and Rhetorical Aspects), Numbers (Social and Rhetorical Aspects), Learning Disabilities (Social, Historical and Rhetorical Aspects), Israel

\section{Introduction: Problematizing the Statistical Idiom}

Samuel Kirk coined the term learning disabilities in 1963 [1]. Since then and during the 1960s the field of dis-

How to cite this paper: Katchergin, O. (2015) How Many Learning Disabled Are There? The Rhetorical Power of Statistics in the Israeli Discourse on Learning Disabilities. Open Journal of Social Sciences, 3, 155-166. 
abilities referred to a specific clinical condition that distinguished it from lack of success in studies [2]. With the passage of time, social, political, economic and scientific factors brought about an expanding application of this diagnosis for the population [1]-[3], so that nowadays the proportion of the learning disabled in the USA is estimated to be about $20 \%$ of the entire student population [4]: Even though only about $5 \%$ have been identified so far, data suggest that an additional 15\% or even more suffer of learning disabilities [4]. In Israel, the proportion of learning disabled is estimated to be about $10 \%-15 \%$ of the entire student population [5]. Other local estimates consider the proportion of the learning disabled to be about $5 \%-20 \%$ [6] or even as high as $30 \%$ of students [7].

Concomitantly with the sharp increase in the proportion of those labeled as learning disabled, over the years, there was a decrease in the proportion of those defined as suffering from other disorders, such as retardation [8]. One of the reasons for this is the connotative difference between the two concepts. Concepts like "mental retardation" or "emotional and behavioral disorders" assign a negative label to the person described, while the concept "learning disabilities" is considered more neutral. In tandem with the actual increase in the proportion of those considered learning disabled, the discourse in customary use in the field acted to create and disseminate statistical statements about the broad range of the learning disabled. In this regard statistical claims about learning disabilities in Israel exemplify their important rhetorical and political role in the construction of social problems ${ }^{1}$. As Spear-Swerling and Sternberg [10] put it, it seemed as though a plague causing learning disabilities had descended on American society.

This article does not intend to estimate the real proportion of the learning disabled in Israel, but to examine the rhetorical dimension of the discourse. I argue that, in the discourse, the statistical idiom has come into customary use and that, even though locally it lacks any valid empirical foundation, it is employed as the basis for legitimizing the field of disabilities and the practices it uses ${ }^{2}$.

In the first part of this article, I will lay out assertions from the fields of sociology of knowledge and of science and from associated research fields: the rhetoric of science, critical discourse analysis of science and the rhetoric of statistics. Likewise, I will interpolate the historical background for the growth of the discourse on disabilities in the United States, and contemporary critiques of the disabilities discourse will be presented. Then I will discuss the definitions in customary use in the Israeli discourse on learning disabilities, referring to the American background in which they are rooted. In the second part of the article, one central discursive idiom in customary use will be analyzed: the statistical idiom that refers to the percentage of the disabled in the population. In this part I will elucidate how major assertions in the Israeli disabilities discourse evolve and are shaped textually and rhetorically so that they become so-called scientific facts.

\section{The Sociology of Knowledge, the Rhetoric of Science, and the Rhetoric of Statistics}

This article is based on the paradigm of social construction which views reality as a product of processes of social construction [11] [12]. According to this paradigm, even knowledge that is considered scientific or researched does not represent reality or nature, but rather the socio-political forces and interests that brought about its creation [11] [12].

Berger and Luckman [11], among the founders of this school, considered the institutions and the social structures to be products originating from protracted human action, and that after they are well established, they force themselves on human agents, compelling them to act along lines that they allow, and thereby make their presence felt as though they were an objective reality. Nevertheless, the constructed nature of the reality makes it possible to introduce changes through everyday negotiations between the agents holding various positions in this regard [13].

The sociology of knowledge addresses the ways in which social organizations contribute to the formation of systems of knowledge [14]. This discipline investigates the processes of formation, preservation and transmission of knowledge in local and broader socio-cultural contexts. It focuses on the power relations in which the system of knowledge is embedded. According to Bourdieu [15], academic knowledge simultaneously reflects and reproduces political hierarchies and broad social distinctions, whereas Foucault [16] [17]) viewed bodies of

\footnotetext{
${ }^{1}$ For more on the important role statistics plays in campaigns to construct, create or defuse claims about new social problems see [9].

${ }^{2} \mathrm{An}$ "idiom" is an explicit narrative assumption firmly grounded in the discourse community of experts. The truth of the idiom is not a matter of question for the experts belonging to that discourse community.
} 
knowledge as methods for exerting power. In his book, Madness and Civilization: A History of Insanity in the Age of Reason [16]), for example, Foucault argued that, during the course of the historical formation of the science of psychiatry, its subjects became "disturbed" persons requiring therapy.

Insofar as this relates to the field of disabilities, the historical growth of clinical and research knowledge enabled the construction of learning disabled subjects and the formation of treatable disabilities able to be supervised. Foucault's genealogical method that tracked the historical roots and transformations of psychiatric knowledge-power is given empirical expression in the present article through the analysis of the processes of evolution of the statistical idiom in the Israeli disabilities discourse.

The sociology of scientific knowledge examines the discursive methods and the practices by means of which scientists learn about the objects of their research as objects without context [18] [19]. This branch of sociology, which challenges essentialist perceptions of knowledge and scientific activity, focuses on processes of argumentation, that is to say the rhetorical and textual methods by means of which scientific truths are formed [20].

The rhetoric of science [21] [22] and critical discourse analysis [23] undermine the pretensions of scientific writing to be technical, smooth, unemotional, impersonal and factual, and prove that practices of selection, organization and textual interpretation are exerted on it too. The assumption on which the scientific texts are based, their assertions, terminologies, metaphors and methods of textual construction are rhetorical tools with persuasive effect; even the references, diagrams, formulae, and dry numbers are part of the repertoire of rhetorical tools of the text. In this context, it should be noted that statistical theory (and statistical methods) itself is a body of knowledge that developed in parallel to the modern states' search for new ways of defining their populations and of controlling them [24]. Moreover, the statistical body of knowledge is in essence rhetorical [25]. Thus the explanation of the statistical idiom in this article fits in with critical literature examining the rhetorical and political dimension of manipulations and statistical presentations [9] [25] [26].

Scholars of the school of social construction argue that clinical knowledge, usually perceived as objective and neutral, is socially constructed [27]. According to this social model, the clinical entities are inventions whose origins are social rather than being discoveries that are not connected to them. By means of scientific ideology, terminology and technology, these clinical entities are formed in the framework of the psycho-medical model that creates an increasing number of behavioral categories able to be clinically diagnosed that are characterized as distinct mental and physical qualities [28] [29]. The psycho-medical model has become the main model by means of which people think, experience, and understand their problems and their lives and the world. This model reduces their understanding of social phenomena to symptoms that are purported to be evidence of disorders or illness.

The psycho-medical discourse is spread by means of social carriers that ratified its findings in practices and everyday utterances: professionals who function as an army of locators, diagnosticians, classifiers, and therapists; the human objects labeled with its terminology; organizations like bureaucratic institutions or associations providing assistance; and other social sites in which representations and cultural images of disorders, illnesses and problems requiring clinical supervision and treatment were created and replicated.

The psycho-medical discourse is applied to ever-increasing fields of human experience and thereby expands the clinical categories and the professional communities. Thus there is considerable medicalization of the educational space through the introduction of clinical professionals and the adoption of medical and psychological models to explain educational and social phenomena. One of the expressions of this is the adoption of chemical solutions (such as medications) and abandoning the pedagogical solutions no longer considered valuable [30].

At the same time that the learning disabilities clinical discourse was developing in the United States and was becoming the largest clinical category in special education, criticisms of it were also developing and becoming more sophisticated. According to those criticisms, the penetration of professional terminology into everyday language, technological advances and statistical data created the impression of a consolidated clinical body of knowledge, monolithic and objective, while obscuring the social relationships and the historical and political disputes in which it was embedded [31].

The criticisms touch on a variety of subjects perceived as central to the very definition of the field, including the theoreticization of learning disabilities, the etiology, epidemiology, diagnostic boundaries, diagnostic criteria, assessment procedures, therapeutic methods, prognoses, and educational policy [8] [32]-[36]. Studies have shown that many of the practitioners in the education system ignored the official definitions and the indicators that were considered objective [37] [38] so as to ensure that the students would benefit from assistance in their studies and from other resources to which those diagnosed with learning disabilities are entitled [37] [39] [40]. 
Another incentive for diagnosing students as disabled was the schools' needs to display learning achievements in national testing. Granting an exemption to disabled students raised the average grades of the school [41].

Other types of criticism addressed the epistemic assumptions of the field of disabilities and attempted to challenge the claim of objective pathology. In this vein, attempts were made to conceptualize learning disabilities in alternative ways and to propose new appellations for the phenomenon such as Dysteachia, Dyspedagogia [42] and Teaching Disabilities [43] which placed the emphasis on the immediate educational environment. The critics claimed that most of the learning disabled did not suffer from an organic problem, but from environmental deprivation [44]. Others claimed that the term "learning disability" should be abolished or, at least fundamentally changed [45] [46].

Other criticisms from the field of education identified learning disabilities as organizational pathologies originating in the bureaucratic non-adaptive character of the schools [47] and in the medicalization of failure which absolves teachers and the system from accepting responsibility [48]. Learning disabilities were even presented as a diagnostic scandal [49], and imaginary disease [50] and a myth [51]. These claimed that the source of the learning difficulties lay in the schools themselves, that is in the teachers, the curricula and teaching methods. It was argued that the widespread models of learning disabilities were characterized by an incorrect reductionist epistemological assumption [52] according to which learning disabilities originated internally. There were even those who asserted that labeling students had destructive implications for their self-esteem and social image [48] [50].

In the recent decade many studies have been published based on a critical discursive orientation that undermine the medical model and the positivistic and functionalistic philosophy on which the disabilities discourse is based. The centrality of the educational viewpoint was emphasized through the creation of subjects susceptible to disciplining, medicalization, objectivization and exclusion [53]. These studies viewed the phenomenon of disabilities as the product of cultural crafting [54], social construction [55], of discursive practices [56] [57] and of myths [58].

The following survey of the criticisms gives just a sampling of the prolific critical discourse in the United States. This discursive heterogeneity is not consistent with the absence of well-reasoned criticisms in this field in the Israeli academic discourse. Similarly, there is almost no academic literature in Israel that examines learning disabilities from sociological, anthropological, philosophical, cultural or historical points of view. It can be said that from the discursive viewpoint, the debate on learning disabilities in Israel is largely technically and scientifically hobbled ${ }^{3}$.

\section{The Historical Development of Disabilities}

It is apparent that the discourse on learning disabilities, including the number of people identified as being disabled, has been growing in recent years. Professionals in the field have improved practices of locating, diagnosing, treating, financing and researching, and according to data provided by experts in academia and the Ministry of Education, at least $10 \%$ - 15\% of the entire population suffer from learning disabilities. Less cautious estimates indicate that the rate of disabilities approaches some one-third of the population [65].

The rapid spread of learning disabilities is not perceived as a phenomenon that requires explanation, and, at most, it is described in the professional literature as a product of the development of knowledge in the field and of heightened awareness about disabilities among the public. Motivations that are not identified as scientific, such as economic and political reasons, are relegated to the sidelines of the discourse as being extraneous to the logic and technology of the field. Ong-Dean [66] analyzed all the political, economic, professional and cultural motivations in the United States that fashioned fertile ground for the consolidation of the learning disabilities discourse and the popularity which it enjoys. His main assertion was that the channel of learning disabilities became established in the United States in response to the initiatives and pressure of white parents who were well-off economically and culturally and who wanted to enlist the resources of the education system to help their struggling children. In other words, the formation of the new clinical category served these parents as a mechanism to keep their children in the normative educational framework, while maximizing their learning achievements and reproducing class privileges. Similar findings were evident in the study conducted in Israel [38] [63] [64]. Educated parents from Ashkenazi backgrounds with cultural and economic capital played a key role in the growth of the disabilities discourse. In Israel too, the disabilities discourse served as a tracking channel within

${ }^{3}$ To date, few articles have been written on learning disabilities in Israel from a sociological point of view. On these studies, see [59]-[64]. 
the education system for the upper socio-economic class of the population. Children from this population who were identified as having disabilities were granted various concessions and exemptions from learning tasks, were given school resources and positive labeling as intelligent and moral ${ }^{4}$. At the same time, the diagnosticians enjoyed a stable and well-established audience who needed their services, and especially benefited from the scientific seal of approval that justified granting privileges to the children. In another study [62] it was found that the popularity that this field enjoyed arose from being freed from negative labeling. Those diagnosed as disabled were no longer lazy or stupid, but intelligent people with a specific neurological disorder.

The year 1963 is considered the date that the field was founded [1] [69] [70]. The founding of the field is attributed to Samuel Kirk who defined learning disabilities thus:

A learning disability refers to a retardation, disorder, or delayed development in one or more of the processes of speech, language, reading, writing, arithmetic, or other school subject resulting from a psychological handicap caused by a possible cerebral dysfunction and/or emotional or behavioral disturbances. It is not the result of mental retardation, sensory deprivation, or cultural and instructional factors ${ }^{5}$.

The concept was introduced into everyday use in the United States by a pressure group of parents which organized itself in 1963 as The Association for Children with Learning Disabilities” [72] [73]. Thereafter, other parent associations were formed across the United States and an enormous amount of popular literature on disabilities, their origins and their significance were published.

The concept "learning disabilities" flourished in the territory of special education largely due to the pressure exerted by parents who were seeking ways of smoothing the paths of their children who had difficulty with their studies and whose difficulties had not been explained. The literature that deals with the development of the field of disabilities notes that the parents who contributed to the establishment of the field were white and middleclass [3] [74]. There are also references to the fact that parents collaborated with experts in special education so as to find a way to prevent their children from being labeled mentally retarded, having behavioral problems or cultural deprivation. However, these references were pushed aside. That period is generally described as one in which parents, professionals and public officials joined together in efforts to develop a valid and accepted definition of learning disabilities [69] in order to assist their children and reduce their difficulties and their distress.

Since the 1960s many other definitions of learning disabilities have been formulated and have been used in the contexts and circumstances of each case up to the present.

\section{Learning Disabilities Definitions in Israel}

The two most commonly used definitions in Israel are that of the (American) National Joint Committee on Learning Disabilities (NJCLD) of 1994 and that of the American Psychiatric Association (APA) of the same year. The Circular Letter of the Director-General of the Ministry of Education (2003-4/4B) determined that "the characteristics of learning disabled children are based on the formal definitions accepted by broad circles of professionals in the field of learning disabilities" [75]. The two definitions are cited immediately thereafter:

Learning disabilities is a general term that refers to a heterogeneous group of disorders manifested by significant difficulties in the acquisition and use of listening, speaking, reading, writing, reasoning, or mathematical skills.

These disorders are intrinsic to the individual, presumed to be due to central nervous system dysfunction, and may occur across the life span. Problems in self-regulatory behaviors, social perception, and social interaction may exist with learning disabilities but do not, by themselves, constitute a learning disability.

Although learning disabilities may occur concomitantly with other disabilities (e.g., sensory impairment, mental retardation, serious emotional disorders), or with extrinsic influences (such as cultural differences, insufficient or inappropriate instruction), they are not the result of those conditions or influences [76].

Learning disorders are diagnosed when the individual's achievement on individually administered, standardized tests in reading, mathematics, or written expression is substantially below that expected for age, schooling, and level of intelligence. The learning problems significantly interfere with academic achievement or activities of daily living that require reading, math, or writing skills [77].

${ }^{4}$ On the early assertions about the learning disabilities category being a privileged diagnosis of the white middle-class population, see [44] [67] [68].

${ }^{5}$ See the definition in [71]. 
Researchers and professionals in the field of disabilities tend to base their definitions on those of the NJCLD and APA so as to reinforce the validity of their statements, and the professional positions that grew up amongst the American pressure groups were cited, translated, and became established in the Israeli field without any critical examination.

Finally, the Learning Disabilities Unit in the Ministry of Education has adopted two main criteria for identifying learning disabilities: "a significant, persistent disparity between the learning achievements of the student and the achievements expected of him according to his age and class level"; and "a significant disparity between the learning achievements of the student and his intellectual abilities, as revealed in objective intelligence quotient tests” ([78], p. 15). These criteria have also been adopted by diagnostic and assistance centers at universities and colleges ${ }^{6}$.

\section{Analyzing the Statistical Idiom in the Learning Disabilities Discourse}

\section{The Statistical Idiom: The Extent of the Phenomenon as Viewed by the Israeli Discourse}

It is very difficult to determine the exact number of the learning disabled in Israel, for there is no central body recording all the data on those diagnosed as disabled, nor has there been any survey on the extent of the phenomenon. The official position of Learning Disabilities Unit of the Ministry of Education as well as the position of most of the researchers in the field is that the number is at least $10 \%$ of the population. A 2007 publication of the Unit claims that the proportion of learning disabled students is between $10 \%$ and $20 \%$ and, in the opinion of many researchers and professionals, the percentage is far higher. However, none of these base their claims on any statistical data, and therefore it seems that the claim that at least $10 \%$ of the population suffer from learning disabilities has become a kind of professional assumption requiring no verification ${ }^{7}$.

From the inception of the debate on disabilities, there was already a prevailing feeling among those dealing with it that the numbers were constantly on the increase: " the number of children referred to the mental health clinics and diagnosed as learning disabled and brain damaged has increased in recent years” ([85], p. 12); "Atrend that has been identified as an irrevocable outcome of the development of medical knowledge, together with heightened awareness of the problem on the part of the public" ([86], p. 3); "In the United States today, close to eight million children suffer from learning and behavioral disorders linked to learning disabilities. How large is this population in our country? No one has paid attention for they are dispersed among regular and special classes ([87], p. 30). Kidron [88]-[90] who was one of those in the forefront of the disabilities field in Israel claimed, in a number of works that the proportion of children suffering from learning disabilities is $10 \%$. It is evident that her views greatly influenced the adoption of the statistical determinant; in the Lexicon of Education and Teaching [91] her statements were quoted and it was claimed that between $4 \%$ and $15 \%$ of the population of children in Israel are assessed as having learning disabilities. Haver, too, ([92], p. 18) asserted, basing himself on Kidron, that: "In Israel the incidence of all learning disabled children-those requiring a special education framework and those able to be partially or completely mainstreamed into regular education-is estimated to be between $10 \%$ and $15 \%$ of the population of children." However, it is not clear from her publications on what she bases these estimates ${ }^{8}$.

Perplexity about the sources of the statistical estimates has not gone unmentioned in the research literature, but they have remained suppressed and not well developed. Rahmani ([95], p. 62) for example, has quoted Schmidt who, as early as 1975 argued: "It is not logical to believe that more than $10 \%$ of the population of

\footnotetext{
${ }^{6}$ These disparity criteria have been the subject of many criticisms in American literature too. See [79] [80]. In Israel these criteria are still formally and unequivocally accepted as valid.

${ }^{7}$ The media discourse seems to display much higher percentages of the learning disabled in Israel: $31 \%$ of the Jewish sector receives concessions in the matriculation examinations [81]. 20\% of the students were entitled to concessions in 2007. Furthermore, 30\% of teenagers in the center of the country have undergone diagnosis in the last three years [82]. There are certain schools in the general education system in which the proportion of those granted concessions in the matriculation examination is between $30 \%$ and $40 \%$ [83]. A survey conducted in July 2007 found that attention deficit disorder or learning disabilities are common occurrences in the Israeli population and one-third of the parents of children aged 6-18 reported that at least one of their children suffered from one of them [84].

These data purport to show that Israel has become a learning disabilities super-power. The proportion of concessions granted is infinitely greater that the proportion of concessions granted in Western countries, including Canada, Britain, Germany, and the United States. We must qualify this by saying that the number of Israeli students with learning disabilities is derived from an approximation of the existing information about the number of those granted concessions in the matriculation examinations, but not all those receiving these concessions are learning disabled.

${ }^{8}$ See also [93]. The only source for the estimate of the extent of the phenomenon that is mentioned there is in the Margalit Report of 1997 [94].
} 
children suffer from fine damage to the central nervous system, and are left with acquired disability”, but the majority of his book is devoted to identifying and explicating the connections between brain and learning. Similarly, Darin ([96], p. 180) ${ }^{9}$ argues in relation to dyslexia:

Difficulties in defining it lead to problems in statistical estimates of its distribution... In fact it is not possible to give an accurate estimate of the distribution of real organic dyslexia... All the statistics available summarize the percentage of those who fail to learn to read with no separate accounting for this special group [dyslexics].

Nonetheless, this did not prevent him from determining that the proportion of the learning disabled in the population is at least $10 \%$. Sharan and Sharan [97] gave a conservative estimate that the minimum proportion of learning disabled children in Israel was 2\% - 3\%, but they too state that no data has been collected as yet.

The statistical claim about the increasing proportion of the learning disabled has remained steady and unchallenged in the research literature since the 1990s:

The facts in the education system show an increasing number of children defined as learning disabled... Data from the Ministry of Education indicates that the population of the learning disabled constitutes $10 \%$ of the entire special education population ([98], p. 30).

Since then there has been a sharp rise in the proportion of disabled students in special education, reaching $40 \%-50 \%$ in the 1990s, as reported on the website of the Department of Special Education ${ }^{10}$.

Disabilities researchers argue that the learning disabled are not only the largest group among students defined as having special needs, but have become the largest group of needy students in regular education [100]. Aside from the special education and mainstreamed students, there is a repeated claim that many of the disabled students are studying in regular classroom with no documentation about their disability. On this basis, it has been argued that the estimate of the proportion of the learning disabled as $10 \%$ is an under-estimate, and that in fact their real proportion is likely to be twice or three times the accepted estimate. In 2004, Regev argued, without evidence, that the number of the learning disabled is at least double the estimation in the Margalit report, which in 1997 estimated that some 10\% of all students in Israel are diagnosed as learning disabled [101]. In a later publication of the Learning Disabilities Unit, too, it was noted that up to $20 \%$ of the entire student population had learning disabilities [78], and it stated that this estimate was by way of an assumption.

Since the estimated number of the disables is so great, the need arose for an educational response, in general, and for involving experts in disabilities, in particular. The statistical claim about the high percentages contributed to the formation of a rhetoric of educational crisis in the style of "an educational problem of the first order, requiring immediate treatment" ([102], p. 128) and to converting the assumption into a fact. "This fact mandates appropriate educational treatment” warned Binshtok [78] in a Ministry of Education circular addressed to the parents of children with difficulties. Criticism of the statistical assertions, questioning the lack of research evidence and attempts at a methodical evaluation of the data are almost nowhere to be found. Similar findings came to light in interviews with professionals in the field. The latter, by and large, referred to the high proportion of the disabled and based their statements on the literature in the field.

Krampf [103] proposed the use of the term "the metaphysics of factuality" to present a particular stream in modern scientific and administrative culture which relates to numbers and to preferred quantities as a form of representation. He argues that academic discourse communities tend to confer objective scientific status on numbers more than on other forms of representation. Statistical knowledge forms objects that are perceived as givens and as worthy of being organized by science, society and the state. Porter [104] argues that quantifying and using mathematical, statistical and formalistic methods are part of the professional toolbox in the struggle for an objective image, free of values and political elements.

That being the case, the theoretical statistical claims of the experts and professionals in the field of disabilities can be viewed as statements aimed at aiding in the creation of a sense of urgency about the need to find a therapy for the new manifestation and also to establish the foundations for the legitimacy and the essential nature of the field of diagnosis and treatment that is being formed. This was despite the fact that most of the statistical

\footnotetext{
${ }^{9}$ Darin is considered to be one of the founding fathers of the field of disabilities in Israel.

${ }^{10}$ See, Ministry of Education, 2007 [99]; it is important to note that the only existing data concerns the population registered in the framework of special education schools. There are no data about the proportion of students who are mainstreamed or about those who have been given various concessions, exemptions, or special conditions within the general education system.
} 
claims about the proportion of the disabled, on which the field based itself from its inception, were not based on comprehensive national surveys. Furthermore, most of them were presented to the reader at face value, with no reference to their empirical origins, and, in the Israeli context, it was even explicitly noted that there were no reliable data as yet.

The Israeli researchers based themselves on the American studies that argued for a high proportion of learning disabled in the population ${ }^{11}$. That is to say that Israeli data alone were not a sufficient rhetorical tool to transmit the message about the large statistical proportions. Greater validity is accorded to numerical data from the rest of the world, and in this case, from America. Even professionals who were interviewed for the article claimed that it was a case in which the proportion of those afflicted was $10 \%$ of the population, and as support for this statistical assertion they quoted Israeli and American sources ${ }^{12}$.

The theoretical statistical claims have, for the most part, not changed in the last 50 years since the foundation of the disabilities field. Even so, the numbers used by the professionals varied from 3\% to $30 \%$, with the most frequent estimate being $10 \%$. In any event, the experts' statistical statements, rather than reflecting empirical data, acted to bolster the discursive rhetoric.

\section{Afterword}

The intention of this article is to expose the vagueness enshrouding the term "learning disabilities", through the use of textual analysis and by means of sociological tools of knowledge and science and tools from related fields like the rhetoric of science, critical analysis of scientific knowledge and rhetoric of statistics. In the arena of research and treatment in Israel, this term is used to indicate the existence of a distinct clinical category, uniform and objective. But in comparison to the global discourse it is clear that the Israeli definitions are simplistic and that, in effect, the field of learning disabilities is fraught with disagreements and features discursive heterogeneity ${ }^{13}$.

On the background of the cultural contexts in which the field is situated, it is found that the statistical idiom not only reflects essential claims, but it is a rhetorical and stylistic device [105] whose aim is to buttress the field's legitimacy and the practices customarily used in it by melodramatically contributing to the creation of a sense of urgency about the need to diagnose more children and to find an appropriate therapy. Thus, it operates as a frightening device in a similar way to other cases in which statistical data are used to raise public anxiety especially when it comes to problems associated with children [106]. This idiom has become part of the obvious aspects of the research and professional debate, and it is possible that the reason for this is the symbolic capital associated with working assumptions originating in the United States, as well as the symbolic capital associated with the science of statistics [25].

To use the terms of the scholar of critical discourse, Van Dijk [107], the present article has focused on "semantic" analysis of scientific texts and interviews with professionals and there is a need for additional studies to examine other discursive levels ("syntactic", "interactive" etc.), as well as the ways in which the disabilities discourse is put into practice in the Israeli field of education with a special emphasis on the use of numerical and statistical claims by non-statisticians in that field. An examination of this kind will necessitate the uncovering of the interrelations between the statistical idiom and the broad contexts and social and professional interests. For example, an examination should be undertaken of how the statistical idiom was shaped into a scientific fact in Israel on the backdrop of neo-liberal economic trends and the tendency to medicalize the field of education.

Following Van Dijk [107], the article illuminates the textual dimension and the discursive dimension of the field of disabilities. Specifically, it analyzes the strategical role of the statistical idiom in the structure of learning disabilities texts. Future studies are likely to relate this idiom to its mobilization in social, political and institu-

\footnotetext{
${ }^{11}$ For example, Sharan and Sharan [97] mentioned two American studies in order to refer to estimated numerical data about the disabled in Israel. Then as now, in a book recently published, the author was required to refer to the proportion of the disabled in America ([65], p. 74): "In 1987, an American committee, the Interagency Committee on Learning Disabilities concluded that 5\% to $10 \%$ are reliable estimates of the percentage of people in the population that are affected by learning disabilities. The American Department of Education (1998) reported that more than $5 \%$ of all the school-age children receive special education services in the framework of regular education due to learning disabilities." To be perfectly accurate, in both those cases the authors based themselves on local data too (Sharan and Sharan mentioned a sample of 50 kibbutzim, and Levy mentioned contradictory data from Merom and Uziel in 2001 and from the Margalit report of 1997).

${ }^{12}$ Many of the interviewees relied on the $10 \%$ indicator (even though they had no empirical support for this number). It is possible that the use of this number originated in the intuitive borrowing of statistical claims from other fields of knowledge. In any event, this rhetorical usage necessitates additional research.

${ }^{13}$ See [38].
} 
tional contexts. There is a need to continue to examine the way the field of education operates via discursive idiomatic mechanisms to reproduce and inflate the learning disability category, and to uncover the influence that larger cultural, economic and professional forces have on the field of disabilities.

\section{References}

[1] Wong, B.Y.L., Graham, L., Hoskyn, M. and Berman, J., Eds. (2008) The ABCs of Learning Disabilities. 2nd Edition, Elsevier Academic Press, San Diego.

[2] Kavale, K.A. and Forness, S.R. (1985) The Science of Learning Disabilities. College-Hill, San Diego.

[3] Sleeter, C.E. (1986) Learning Disabilities: The Social Construction of a Special Education Category. Exceptional Children, 53, 46-54.

[4] National Center for Learning Disabilities (2014) The State of Learning Disabilities. 3rd Edition, New York.

[5] Hedd, S. (1990) Learning Disabilities_-Young and Adults: Parental Expectations and Conflicts in the Family. Master Thesis, Tel-Aviv University, Tel-Aviv. [In Hebrew]

[6] Naiman, R. (2006) Educational Intervention for the Advancement of Pupils with Learning Disabilities. Ministry of Education. [In Hebrew]

[7] Heiman, T. (2000) Learning Disabilities. The Open University, Tel-Aviv. [In Hebrew]

[8] Lyon, G.R. (1996) Learning Disabilities. In: Marsh, E. and Barkley, R., Eds., Child Psychopathology, Guilford Press, New York, 390-434. http://dx.doi.org/10.2307/1602494

[9] Best, J. (2001) Damned Lies and Statistics: Untangling Numbers from the Media, Politicians, and Activists. University of California Press, Berkeley.

[10] Spear-Swerling, L. and Sternberg, R.J. (1998) Curing Our “Epidemic” of Learning Disabilities. Phi Delta Kappan, 79, 397-401.

[11] Berger, P.L. and Luckman, T. (1971) The Social Construction of Reality: A Treatise in the Sociology of Knowledge. Harmondsworth, Penguin Books, Middlesex.

[12] Sismondo, S. (2010) An Introduction to Science and Technology Studies. 2nd Edition, Wiley-Blackwell, Malden.

[13] Gergen, K. (Ed.) (2001) Social Construction in Context. Sage Publications, London.

[14] Swidler, A. and Arditi, J. (1994) The New Sociology of Knowledge. Annual Review of Sociology, 20, 305-329. http://dx.doi.org/10.1146/annurev.so.20.080194.001513

[15] Bourdieu, P. (1988) Homo Academicus. Polity, Cambridge.

[16] Foucault, M. (1967) Madness and Civilization: A History of Insanity in the Age of Reason. Mentor Books, London.

[17] Foucault, M. (1980) Power/Knowledge: Selected Interviews and Other Writings, 1972-1977. Gordon, C. (Ed.), Random House, New York.

[18] Latour, B. and Woolgar, S. (1986) Laboratory Life: The Social Construction of Scientific Facts. Princeton University Press, Princeton.

[19] Lynch, M. (1993) Scientific Practice and Ordinary Action: Ethnomethodological and Social Studies of Science. Cambridge University Press, Cambridge.

[20] Shapin, S. (1995) Here and Everywhere: Sociology of Scientific Knowledge. Annual Review of Sociology, 21, 289321. http://dx.doi.org/10.1146/annurev.so.21.080195.001445

[21] Bazerman, C. (1988) Shaping Written Knowledge: The Genre and Activity of the Experimental Article in Science. University of Wisconsin Press, Madison.

[22] Gross, A.G. (1990) The Rhetoric of Science. Harvard University Press, Cambridge, MA.

[23] Gilbert, G.N. and Mulkey, M. (1984) Opening Pandora’s Box: A Sociological Analysis of Scientists’ Discourse. Cambridge University Press, Cambridge.

[24] Hacking, I. (1990) The Taming of Chance. Cambridge University Press, Cambridge.

[25] McCloskey, D. (1993) Rhetoric within the Citadel: Statistics. In: Willard, C.A. and Goodnight, G.T., Eds., Public Argument and Scientific Understanding, 485-490.

[26] John, I.D. (1992) Statistics as Rhetoric in Psychology. Australian Psychologist, 27, 144-147. http://dx.doi.org/10.1080/00050069208257601

[27] Bury, M.R. (1986) Social Constructionism and the Development of Medical Sociology. Sociology of Health and Illness, 8, 137-169. http://dx.doi.org/10.1111/1467-9566.ep11340129

[28] Conrad, P. (1992) Medicalization and Social Control. Annual Review of Sociology, 18, 209-232. 
http://dx.doi.org/10.1146/annurev.so.18.080192.001233

[29] Zola, I. (1978) Medicine as an Institution of Social Control. Sociological Review, 20, 487-504. http://dx.doi.org/10.1111/j.1467-954X.1972.tb00220.x

[30] Petrina, S. (2006) The Medicalization of Education: A Historiographic Synthesis. History of Education Quarterly, 46, 503-531. http://dx.doi.org/10.1111/j.1748-5959.2006.00030.x

[31] Sleeter, C.E. (1995) Radical Structuralist Perspectives on the Creation and Use of Learning Disabilities. In: Skrtic, T.M., Ed., Disability and Democracy: Reconstructing Special Education for Postmodernity, Teachers College Press, New York, 153-165.

[32] Fuchs, D., Fuchs, L.S., Mathes, P.G., Lipsey, M.W. and Roberts, P.H. (2001) Is “Learning Disabilities” Just a Fancy Term for Low Achievement? A Meta-Analysis of Reading Differences between Low Achievers with and without the Label. Paper Presented at the Office of Special Education Program's LD Initiative Conference, Washington DC, 27-29 August 2001.

[33] Gerber, M.M. and Semmel, M.I. (1984) Teacher as Imperfect Test: Reconceptualizing the Referral Process. Educational Psychologist, 19, 137-148. http://dx.doi.org/10.1080/00461528409529290

[34] Katchergin, O. (2014) "Learning-Disabilities” as a "Black Box": On the Different Conceptions and Constructions of a Popular Clinical Entity in Israel. Culture Medicine \& Psychiatry, 38, 669-699. http://dx.doi.org/10.1007/s11013-014-9398-3

[35] Lyon, G.R. (1987) Severe Discrepancy: Theoretical, Psychometric, Developmental and Educational Issues. Learning Disabilities Research, 3, 10-11.

[36] Mercer, C.D., King-Sears, P. and Mercer, A.R. (1990) Learning Disabilities Definitions and Criteria Used by State Education Departments. Learning Disability Quarterly, 13, 141-152. http://dx.doi.org/10.2307/1510657

[37] Gottlieb, J., Alter, M., Gottlieb, B.W. and Wishner, J. (1994) Special Education in Urban America: It’s Not Justifiable for Many. The Journal of Special Education, 27, 453-465. http://dx.doi.org/10.1177/002246699402700406

[38] Katchergin, O. (2009) Studying (in) Disorder: Sociological Perspective on Learning Disabilities in Israel. PhD Dissertation, Tel-Aviv University, Tel-Aviv. (In Hebrew)

[39] MacMillan, D.L., Siperstein, G.M. and Gresham, F.M. (1996) A Challenge to the Viability of Mild Mental Retardation as a Diagnostic Category. Exceptional Children, 62, 356-371.

[40] Shepard, L., Smith, M.L. and Vojir, C.P. (1983) Characteristics of Pupils Identified as Learning Disabled. American Educational Research Journal, 20, 309-331. http://dx.doi.org/10.3102/00028312020003309

[41] Brantlinger, E. (1997) Using Ideology: Cases of Nonrecognition of the Politics of Research and Practice in Special Education. Review of Educational Research, 67, 425-459. http://dx.doi.org/10.3102/00346543067004425

[42] Lerner, J.W. (1985) Learning Disabilities: Theories, Diagnosis, and Teaching Strategies. 4th Edition, Houghton Mifflin, Boston.

[43] Bateman, B. (1974) Educational Implications of Minimal Brain Dysfunction. Reading Teacher, 27, 662-688.

[44] Coles, G.S. (1987) The Learning Mystique: A Critical Look at Learning Disabilities. Pantheon Press, New York.

[45] Algozzine, R. (1985) Low Achiever Differentiation: Where’s the Beef? Exceptional Children, 52, 72-75.

[46] Lyon, G.R., Fletcher, J.M., Shaywitz, S.E., Shaywitz, B.A., Torgesen, J.K., Wood, F.B., Schulte, A. and Olson, R. (2001) Rethinking Learning Disabilities. In: Finn Jr., C.E., Rotherham, A.J. and Hokanson Jr., C.R., Eds., Rethinking Special Education for a New Century, Thomas B. Fordham Foundation, Washington DC, 259-287.

[47] Skrtic, T.M. (1999) Learning Disabilities as Organizational Pathologies. In: Sternberg, R.J. and Spear-Swerling, L., Eds., Perspectives on Learning Disabilities: Biological, Cognitive, Contextual, Westview Press, Boulder, 193-226.

[48] Christensen, C.A. (1999) Learning Disability: Issues of Representation, Power and the Medicalization of School Failure. In: Sternberg, R.J. and Spear-Swerling, L., Eds., Perspectives on Learning Disabilities: Biological, Cognitive, Contextual, Westview Press, Boulder, 227-249.

[49] Scriven, M. (1985) Comments on Gene Glass. Paper Presented at the Wingspread National Invitational Conference on Public Policy and the Special Education Task Force of the 1980s, Cited in Hallahan, D.P., Kauffman, J. and Lloyd, J., Introduction to Learning Disabilities, Prentice Hall, Englewood Cliffs.

[50] Finlan, T.G. (1994) Learning Disability: The Imaginary Disease. Bergin \& Garvey, Westport.

[51] McKnight, R.T. (1982) The Learning Disability Myth in American Education. Journal of Education, 164, $351-359$.

[52] Poplin, M.S. (1988) The Reductionistic Fallacy in Learning Disabilities: Replicating the Past by Reducing the Present. Journal of Learning Disabilities, 21, 389-400. http://dx.doi.org/10.1177/002221948802100702

[53] Skrtic, T.M. (2005) A Political Economy of Learning Disabilities. Learning Disability Quarterly, 28, 149-155. http://dx.doi.org/10.2307/1593616 
[54] McDermott, R., Goldman, S. and Varenne, H. (2006) The Cultural Work of Learning Disabilities. Educational Researcher, 35, 12-17. http://dx.doi.org/10.3102/0013189x035006012

[55] Dudley-Marling, C. (2004) The Social Construction of Learning Disabilities. Journal of Learning Disabilities, 37, 482-489. http://dx.doi.org/10.1177/00222194040370060201

[56] Artiles, A. (2004) The End of Innocence: Historiography and Representation in the Discursive Practice of Learning Disabilities. Journal of Learning Disabilities, 37, 550-555. http://dx.doi.org/10.1177/00222194040370061001

[57] Reid, D.K. and Valle, J.W. (2004) The Discursive Practice of Learning Disability. Journal of Learning Disabilities, 37, 466-481. http://dx.doi.org/10.1177/00222194040370060101

[58] Zuriff, G.E. (2007) The Myths of Learning Disabilities. In: Curren, R., Ed., Philosophy of Education: An Anthology, Blackwell Publishing, Hoboken, 291-297.

[59] Ayalon, H. and Margalit, M. (2004) Concessions in Matriculation Exams to Pupils with Learning Disabilities: The Role of School Policy. Megamot, 43, 242-265. (In Hebrew)

[60] Artman, L. (2007) Dizzying Success: Learning Disabilities Diagnosis in the Field of Reading. Education and Its' Environment, 29, 67-81. (In Hebrew)

[61] Artman, L. (2011) The Diagnoses Industry. HedHa’Chinuch, 6, 77-79. (In Hebrew)

[62] Katchergin, O. (2012) So What Is This Thing Called “Learning Disability”? A Discussion of the Definition and Its' Implications. Dvarim, 5, 67-82. (In Hebrew)

[63] Katchergin, O. (2012) Between Negative Stigma (Cultural Deprivation) and Positive Stigma (Learning Disability): The Historical Development of Two Special Education Tracks. Culture Medicine \& Psychiatry, 36, 679-711. http://dx.doi.org/10.1007/s11013-012-9281-z

[64] Katchergin, O. (2013) “The Good Parent” and "the Other Parent”: Othering and Social Exclusion in Professional Discourse Regarding Learning-Difficulties. Dvarim, 6, 77-98. (In Hebrew)

[65] Levy, R. (2009) Yeledyiḥudi: Ha-zekhutỵeha-etgarle-țapelbo: Ṭipulmeshulav bi-yeladim ‘imleḳuyotlemidah be-misgeret ha-sherut ha-psikhologihinukhi be-'iryatYerushalayim. Ashalim, Jerusalem. (In Hebrew)

[66] Ong-Dean, C. (2009) Distinguishing Disability: Parents, Privilege, and Special Education. The University of Chicago Press, Chicago.

[67] McLaughlin, M. and Owings, M.F. (1993) Relationships among States’ Fiscal and Demographic Data and the Implementation of P.L. 94-112. Exceptional Children, 59, 247-261.

[68] Smith, M.L. (1982) How Educators Decide Who Is Learning Disabled. Charles C. Thomas, Springfield.

[69] Hammill, D.D. (1990) On Defining Learning Disabilities: An Emerging Consensus. Journal of Learning Disabilities, 23, 74-84. http://dx.doi.org/10.1177/002221949002300201

[70] Sanders, M. (1984) Clinical Assessment of Learning Problems. Ha’Poalim Library. (In Hebrew)

[71] Hallahan, D.P. and Keogh, B.K. (Eds.) (2001) Research and Global Perspectives in Learning Disabilities: Essays in Honor of William M, Cruikshank. L. Erlbaum Associates, Mahwah.

[72] Armstrong, T. (1987) In Their Own Way: Discovering and Encouraging Your Child’s Personal Learning Style. Jeremy P. Tarcher, Inc., Los Angeles.

[73] Siegel, E. and Gold, R. (1982) Educating the Learning Disabled. Macmillan, New York.

[74] Winzer, M.A. (1993) The History of Special Education: From Isolation to Integration. Gallaudet University Press, Washington DC.

[75] Ministry of Education and Culture (2003) Concessions in Ways of Examinations to Internal Learning Disabled Examinees. General Director Circular-Standing Orders 64/4 (2), Jerusalem. (In Hebrew)

[76] National Joint Committee on Learning Disabilities (NJCLD) (1994) Learning Disabilities: Issues on Definition-Revised. In: NJCLD, Ed., Collective Perspectives on Issues Affecting Learning Disabilities, Pro-Ed, Austin, 61-66.

[77] American Psychiatric Association (1994) Diagnostic and Statistical Manual of Mental Disorders. 4th Edition, American Psychiatric Association, Washington DC.

[78] Binshtok, O. (2007) A Guide to Parents of Pupils with Learning Disabilities. Ministry of Education. (In Hebrew)

[79] Kavale, K.A. and Forness, S.R. (1995) The Nature of Learning Disabilities: Critical Elements of Diagnosis and Classification. Lawrence Erlbaum Associates, Mahwah.

[80] Peterson, K.M.H. and Shinn, M.R. (2002) Severe Discrepancy Models: Which Best Explains School Identification Practices for Learning Disabilities? School Psychology Review, 31, 23-33.

[81] Kashti, Y. (2009) More than a Quarter of High School Pupils in Israel Get Concessions in the Matriculation Examinations. Ha’aretz, 9 December 2009. (In Hebrew) www.haaretz.co.il/news/education/1.1293988 
[82] Valmer, T. (2010) Learning Disabled Empire: Well-Off Get More. Ynet, 17 December 2010. (In Hebrew) www.ynet.co.il/articles/0,7340,L-3995197,00.html

[83] Leibowitz Dar, S.H. (2004) Learning Disabilities Epidemic Is Spreading in Tel-Aviv. Ha’aretz, 2 February 2004. (In Hebrew) www.haaretz.co.il/misc/1.943296

[84] Kalka, A. (2007) The Learning Disabilities.

[85] Arazi, S.H. (1970) Learning Disabilities among Children with Brain Damage—Clinical Diagnosis. Child Development, 1, 10-23. (In Hebrew)

[86] Birch, G. (1970) The Brain-Damage Problem among Children. Child Development, 1, 3-11. (In Hebrew)

[87] Ayalon, O. (1970) Emotional Inhibitions in Learning to Read. Child Development, 1, 28-37. (In Hebrew)

[88] Kidron, R. (1972) Remarks Regarding the Paper of Dr. Shifra Arazi "Learning Disabilities among Children with Brain Damage-Clinical Diagnosis”. Child Development, 1, 24-27. (In Hebrew)

[89] Kidron, R. (1988) Reading, A Diagnostic-Didactic Test. Ministry of Education and Culture, the Pedagogical Secretariat, the Special Education Department, Jerusalem. (In Hebrew)

[90] Kidron, R. (1990) Ram-Example of Diagnosis and Analysis of a Reading Case. Ministry of Education and Culture, Special Education Department with Nitzan Association. Nitzan, Tel-Aviv. (In Hebrew)

[91] Arieli, M., Kashti, Y. and Shalsky, S. (Eds.) (1997) The Education and Teaching Lexicon. Ramot, Tel-Aviv. (In Hebrew)

[92] Haver, D. (1990) “Doesn’t Like to Read”: Multi-Dimensional Treatment of Learning-Disabilities. Ramot, Tel-Aviv. (In Hebrew)

[93] Feldman, D., Lahav-Danieli, Y. and Haimovitz, S.H. (2007) The Accessibility of the Israeli Society for Persons with Disabilities on the Threshold of the 21th Century. Ministry of Law, Jerusalem. (In Hebrew)

[94] Margalit, M. (1997) Report of the Committee for Assessing the Abilities of Learning Disabled Pupils. Ministry of Education, Jerusalem. (In Hebrew)

[95] Rahmani, L. (1985) Brain and Learning: Process and Disabilities. Tel-Aviv University, Tel-Aviv. (In Hebrew)

[96] Darin, A. (1984) Neuropsychology and the Exceptional Child. Oranim, Haifa. (In Hebrew)

[97] Sharan, S.H. and Sharan (1969) Learning Disabilities and Their Correction. Ha'Poalim library, Tel-Aviv. (In Hebrew)

[98] Falk, B. (1992) The Correlation between Categorical Memory and Categorical Thinking among Diagnosed Learning Disabled Children. Bar Ilan University, Ramat-Gan. (In Hebrew)

[99] Ministry of Education. Retrieved in 20 June 2007. http://cms.education.gov.il/EducationCMS/Units/Special/HaagafBepeula/NetuneyKitot/KitotTalmidim.htm

[100] Margalit, M., Molcho, E. and Danino, M. (2002) Examination Concessions to Pupils with Learning Disabilities: Surveying of the Research and Implications. Educational Counseling, 11, 48-63. (In Hebrew)

[101] Regev, R. (2004) Academic Self Efficacy as Mediating between Learning Disabilities, Past Achievements, Parents and Teachers Beliefs in Students Ability, and Future Achievements. Master Thesis. Tel-Aviv University, Tel-Aviv. (In Hebrew)

[102] Balgur, R. (1991) Clarifications and Disagreements Regarding Dyslexia. Megamot, 34, 301-316. (In Hebrew)

[103] Krampf, A. (2011) The Metaphysics of the Fact: The Social Measurement in Historical and Comparative Perspective. In: Hakak, Y., Kacen, L. and Krumer-Nevo, M., Eds., The Limits of Quantification: Critical Perspectives on Measuring and Grading People, Their Behaviors and Achievements, Ben-Gurion University, Be'ersheva. (In Hebrew)

[104] Porter, T.M. (1995) Trust in Numbers: The Pursuit of Objectivity in Science and Public Life. Princeton University Press, Princeton.

[105] Roeh, I. and Feldman, S. (1984) The Rhetoric of Numbers in Front-Page Journalism: How Numbers Contribute to the Melodramatic in the Popular Press. Text \& Talk, 4, 347-368. http://dx.doi.org/10.1515/text.1.1984.4.4.347

[106] Best, J. (1993) Threatened Children: Rhetoric and Concern about Child-Victims. The University of Chicago Press, Chicago.

[107] Van Dijk, T. (2000) New(s) Racism: A Discourse Analytical Approach. In: Cottle, S., Ed., Ethnic Minorities and the Media, Open University Press, Philadelphia, 211-226. 